\title{
Cost effective removal of COD in the pre-treatment of wastewater from paper industry
}

\author{
Joanna Boguniewicz-Zablocka, Iwona Klosok-Bazan, Vincenzo Naddeo
}

Q1 and Clara A. Mozejko

\begin{abstract}
The present paper reveals results of research for cost effective removal of chemical oxygen demand (COD) contained in industrial -paper mill effluent. Not only process efficiency but also wastewater treatment costs are discussed. Different pre-treatment processes are applied aiming to investigate the COD removal before the discharge to municipal sewage network. The objective of this paper is to find the optimal operating conditions for coagulation process. The effect of key operational parameters, including the type of coagulant, initial $\mathrm{pH}$, temperature and coagulant dose, on COD percent removal were investigated. The laboratory experiments confirmed the high efficiency of chemically enhanced mechanical treatment towards COD. The data obtained shows that even low dose of chemicals provides sufficient $\mathrm{COD}$ reduction. The initial $\mathrm{pH}$ of the wastewater had a significant impact on the COD removal. Under the optimal operational conditions $\left(\mathrm{pH}=7.5, \mathrm{~T}=18^{\circ} \mathrm{C}\right)$ the treatment of wastewater from paper industries by coagulation has led to a reduction of 70\% COD for wastewater discharged. In terms of investigated paper industry wastewater PAC appears to be most suitable for treatment of high COD concentration. However, in an economic evaluation of requirements for wastewater treatment, operating costs and associated saving were such that PAX was more favourable.
\end{abstract}

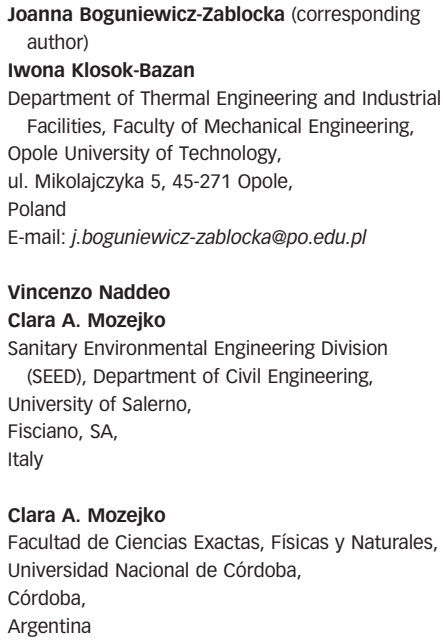
Key words | coagulation, COD, cost effective treatment, industrial wastewater, paper industry

\section{INTRODUCTION}

Paper, whether produced in the modern factory or by the most careful, delicate hand methods, is made up of connected fibre. The fibres can come from a number of sources including wastepaper, cellulose fibres from plants and most notably trees (Agarwal et al. 20I4). It is commonly produced by passing an aqueous cellulosic suspension through a centriscreen or other shear device and draining these purified suspension (BAT 20I0). This scenario causes paper industry, alongside other significant water consumers (Boguniewicz-

Q2 Zalocka et al. 20I7), to be a very water-intensive business consumer. In this way, in 2017, water consumption of paper industry in Poland amounted to $108.3 \mathrm{hm}^{3}$; significant part of this water $(95.8 \%)$ taken by the paper plants came from surface sources, only less than $4 \%$ of the water used for paper production came from underground sources (Central Statistical Office 20I8). Regarding to the volume of water used compared to the volume of production, paper industry may get to consume even $60 \mathrm{~m}^{3}$ of freshwater per each

Q3 tone of paper produced (BAT, Pokhrel et al. 2004; Ashrafi doi: $10.2166 /$ wst.2019.328 et al. 20I5; Molina-Sánchez et al. 20I8). At the same time Q4 these specific industries produce highly polluted wastewater, generated during various processes of pulping and papermaking activities. In 2017, annual volume of wastewater discharged from manufacture of paper and paper products amounted up to $90.1 \mathrm{hm}^{3}$. The most significant part $(95.89 \%)$ is treated by paper mills and then overturned into the environment. However, there are also several factories in Poland that discharge industrial wastewater to the municipal sewage system (Central Statistical Office 20I8). This situation may lead to negative impacts on the environment representing a serious risk to surface water quality. Wastewater discharged into surface water bodies without any particular treatment system can cause adverse effects on aquatic life even at very low concentrations. In order to protect the environment satisfying legal requirements, it becomes necessary for the industry to remove harmful materials from wastewater before is discharged to the environment (Regulation of Infrastructure Minister 2002). 
As the data show, wastewater from paper industry contains a variety of organic and inorganic contaminants that are mostly originating from materials and process used in paper and pulp production. This wastewater is also characterized by a specific colour, mainly due to organic and extractives compounds presence, tannin resins, synthetic dyes, lignin and their degradation products formed by the action of chlorine on lignin during the bleaching process. It should be noted that the effluent characteristics vary according to the applied process and the singular characteristics of each factory. In general, high organic material and suspended solid contents are considered major pollutants of pulp and paper industry effluents (Buyukkamaci \& Koken 20IO). Chemical oxygen demand parameter (COD) describes amount of oxygen taken from the oxidant for chemical oxidation of organic matter and some inorganic compounds (i.e. nitrites, nitrates, sulphates). Biological Oxygen Demand (BOD) measure the oxygen required by microorganisms whilst breaking down organic matter. BOD measures the organic loading of streams and thereby quantifies the dissolved oxygen levels. For instance, the COD of mechanical pulp process effluent changes between 1,000 and $5,600 \mathrm{mg} \mathrm{O} 2 / \mathrm{L}$, it increases up to 2,500$13,000 \mathrm{mg} \mathrm{O} / \mathrm{L}$ in chemical pulp process. Unfortunately pulp and paper mill wastewater has low biodegradability index $\left(\mathrm{BOD}_{5} / \mathrm{COD}\right)$, typically less than 0.4 , clearly showing that paper effluent cannot be treated effectively through conventional biological methods. Several methods have been considered for the removal of COD pollution and colour from the pulp and paper mill effluents. The main treatment processes are primary clarification by sedimentation or flotation and secondary treatment with advanced oxidation, adsorption, membrane filtration and chemical processes should be assessed (Zodi et al. 20II; Ashrafi et al. 20I5; Nwakwere et al. 20I6; Abedinzadeh et al. 2018; MolinaSánchez et al. 2018, Zhuang et al. 2018). The addition of various oxidation agents has been developed in laboratory as a promising way to treat highly polluted effluents

Q5 (Kamali et al. 2019) but in order to be adopted by the industry must have the ability to be easily transferred from labscale installations to full-scale applications. Reduction of COD index is usually considered as a measure of the effectiveness of the wastewater treatment process in the treatment plant. Studies have shown that traditional biological purification does not remove toxic compounds as well as the total content of organic compounds (as COD) and may even lead to the formation of metabolites with even greater persistence and toxicity [BAT]. Coagulation and flocculation processes are one of the best options to treat pulping wastewater using aluminium, ferric chloride, lime, ferrous sulphate and poly aluminium chloride and can be considered as an efficient treatment method to reduce COD, total suspended solids (TSS) and colour of pulping effluent (Rahbar et al. 2006; Wong et al. 2006; Deegan et al. 20II; Yang et al. 2019). The major advantage of chemical treatment is that most COD and TSS are being reduced during this process therefore it can lead to make it more cost effective before secondary treatment as well as removal of colour for effluent (Irfan et al. 20I7; Hang et al. 20I8).

The basic procedural problem of wastewater treatment by chemical coagulation method is the choice of a coagulant and the determination of its optimal dose (Aguilar et al. Q6 2002; Georgiou et al. 2003). Both scenarios, too small or Q7 excess of coagulant dose, lead to a lowering coagulation capacity (Duan \& Gregory 2003). Excess of coagulant dose Q8 can lead to partial release of coagulated sewage sludge as a result of formed sediment peptization in the optimal coagulant dose environment (Ratnaweera 2004). Coagulants unhydrolyzed (e.g., aluminium sulphate) are increasingly displaced by coagulants pre-hydrolysed, because they are believed to be more effective in removing compounds that cause the colour and turbidity of water (Loua et al. 2012).

This paper evaluates the pre-treatment processes with coagulation of paper mill wastewater and examines the effects which they could have on COD removal efficiency. Nowadays modified composite and pre-hydrolized coagulants becoming more and more complicated, regarding their composition, but also more effective, when compared with the traditionally applied reagents. The paper presents the applications of the new generation coagulants, which are recently available on the market and have not been used for paper mill wastewater before. The study compared effectiveness of different coagulants that were tested for different paper mill effluent in wide range of temperature and $\mathrm{pH}$. The coagulation is mainly use to meet the requirements of the recipient's water license pretreated sewage and to avoid increased charges or penalties for overruns permissible concentrations of pollutants in sewage. This paper seeks to fill need by development both cost and an effectiveness comparison for COD removal from wastewater. Also possibility to reuse treated wastewater in processes during paper pulp preparing was considered.

\section{MATERIAL AND METHODS}

Wastewater samples were taken from two different paper mills industries in the Opolskie voivodship in Poland (Figure 1), and tests were done under laboratory conditions. 


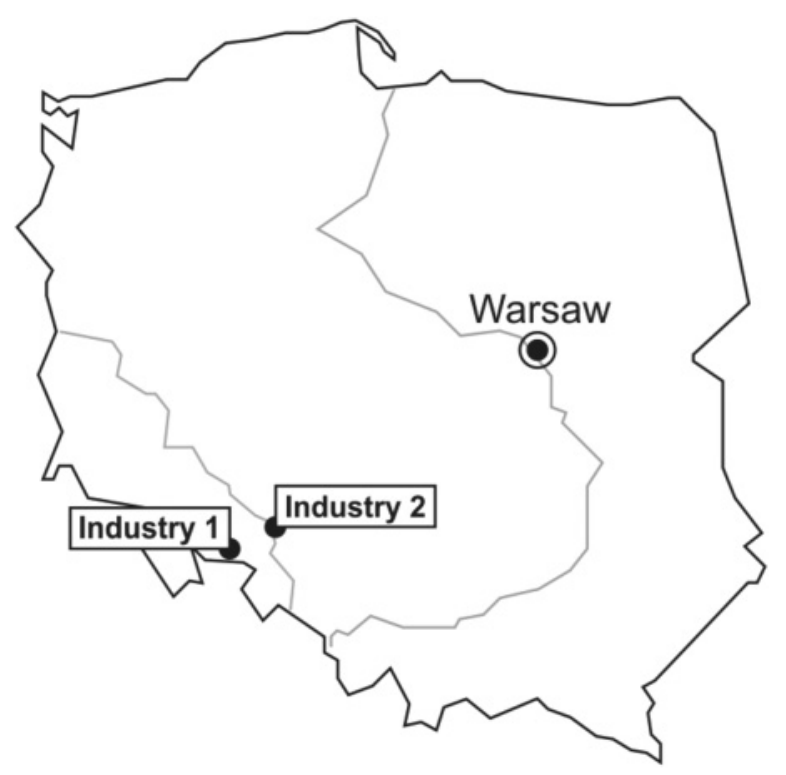

Figure 1 | Map with paper mill location

From each industry few series of raw wastewater were taken after screen bar treatment in industrial plant. The paper mill wastewater samples were collected in 2 liter plastic cans, transported to the laboratory, and used for experiments within $3 \mathrm{~h}$ of sampling. Before starting coagulation tests, wastewater was analyzed determining parameters such as $\mathrm{pH}$, temperature, COD and TSS in the raw wastewater. COD measurements were determined according to the Standard Methods for Examination of Water

Q10 and Wastewater (Lenore 2005). The dichromate reflux method has been selected for the COD determination because it has advantages over other oxidants in oxidizabilitiy, applicatibility to a wide variety of samples, and easy manipulation. COD determination use potassium dichromate (K2Cr2O7) in excess in an acidic medium with the aid of silver sulfate (Ag2SO4) as a catalyst and mercuric sulfate $(\mathrm{HgSO} 4)$ added to remove interference of chlorides. Dichromate oxidizes organic and inorganic matter in the sample, and it is reduced from $\mathrm{Cr}^{+6}$ to $\mathrm{Cr}^{+3}$. The test was performed on the heater until the sample reaches $168^{\circ} \mathrm{C}$ (it cannot pass the 170 degrees). After digestion, excess potassium dichromate is titrated with Mohr salt using ferroin (standard ferrous ammonium sulfate titrant, $0,1 \mathrm{~N} \mathrm{Fe}\left(\mathrm{NH}_{4}\right)_{2}$. $\left.\left(\mathrm{SO}_{4}\right)_{2}\right)$ as indicator. The solution color changes from green to red. The amount of oxidable organic matter, measured as oxygen equivalent, is proportional to the potassium dichromate consumed. The TSS were obtained by centrifugation then drying at $105^{\circ} \mathrm{C}$. Temperature was measured using electronic thermometer PT-411(ELMETRON,Gliwice,Poland) and also electronic pH-meter CP-411(ELMETRON,Gliwice,Poland) with temperature compensation adjustment for $\mathrm{pH}$ value measurement was used. The most commonly used metal coagulants fall into two general categories: those based on aluminium and those based on iron. The first ones include aluminium sulphate, aluminium chloride, and sodium aluminate. The second ones include ferric sulfate, ferrous sulfate, ferric chloride and ferric chloride sulfate (Konieczny 20II).

In the last years, it has been developed pre-hydrolyzed coagulants products; the principal advantages of this are that they are able to function efficiently over wide ranges of $\mathrm{pH}$ and low temperatures. Also they turn to be more economic, because lower doses are required to achieve water treatment goals and less chemical residues are produced (Konieczny 20II; Yang et al. 2016).Aluminum and iron-based coagulants are widely available and commonly used for wastewater treatment, new generation coagulants with additives in the structure in order to improve coagulation performance become more popular. During this study following commercial coagulants were used: FLOKOR 1.2 A; PAX XL 19H; PIX FeCl3. Shortened version of systematic names for all commercial coagulants were used.

The FLOKOR coagulant can be also known as polyaluminum chloride (PAC), and it is a high efficient coagulant with low generation of waste sludge in a wide $\mathrm{pH}$ range, even at low temperatures. This one is known for being highly efficient with low generation of waste sludge. They consist on an aqueous solution of aluminum hydroxy-chloride. In this study PAC - produced in Dempol company in the form of a light gray, density solution of $1.28 \mathrm{gdm}^{-3}$, with $20.68 \% \mathrm{Al}_{2} \mathrm{O}_{3}$ was used. The PAX coagulant belongs to the aluminum group of coagulants, that contains $\mathrm{Al}^{3+}$ as active component with a rage of concentration between 4.5 and 12\%. Here PAX XL19H was used. The PIX belong to the ferric coagulants, that comprise iron sulfates, chlorides and iron chlorosulfates. They are particularly recommended to for removal of phosphorus content from wastewater, for binding of hydrogen sulfide and for wastewater sludge conditioning purposes. PIX - produced by the company Dempol with the approximate chemical formula $\mathrm{Fe}_{2}\left(\mathrm{SO}_{4}\right)_{3}$, in the form of a dark brown $40-42 \%$ solution, with a density of $1.5-1.6 \mathrm{~g} \mathrm{dm}^{-3}$ was used.

Coagulation process was evaluated at laboratory scale and involved utilization of three kinds of coagulants for real industrial wastewater from paper mill industry. Coagulation was carried using each coagulant in different 
temperature and $\mathrm{pH}$ values. Velocity of the mixing was the same for each sample. The time for sedimentation was the same. The coagulation tests were conducted in standard $1 \mathrm{~L}$ glass beakers. The stirring rate was fixed at $100 \mathrm{rpm}$, the coagulant was added under agitation as pure solution using a micro-pipette at a point just below the free surface of the suspension. After $20 \mathrm{~min}$ mixing at $100 \mathrm{rpm}$, the coagulated suspensions were allowed to settle in graduated Imhoff cones for $30 \mathrm{~min}$. The experiment were done using two kinds of real wastewater from different paper mill industries : GZP -Industry 1 and MT - Industry 2. Both paper mills produce mainly toilet paper, which have to have the quality of disintegration when it gets in touch with water, and 12 also napkin paper, which does not have this quality. The process to make it is different, so as a result the wastewater are different according to which paper is making. The parameters value for wastewater used in the laboratory tests are presented in Table 1. As can be seen there are significant differences in the wastewater from different paper industries that depends from diversity of raw products and technology used in industry. These differences in raw wastewater quality affect coagulation process.

Samples were analysed after sedimentation. The effects of working parameters, such as initial $\mathrm{pH}$, temperature and coagulants dose, were studied in an attempt to achieve the optimal treatment conditions to effectively treat these wastewater samples. The optimized parameters were then applied for the treatment of the remaining wastewater samples to validate the treatment efficiency. All experiments were repeated twice, obtained an experimental error within 3\%.

Results allowed to implement the optimal coagulant dose to a case study on site. Case study in site specific condition were in Industry 1 (I1) where the treatment option is main mechanical pre-treatment and coagulation before outflow to municipal sewage network. The chemical and physical properties of wastewater from I1 in site specific condition are presented in Table 2.

Table 1 | Raw wastewater from industry used in laboratory experiment

\begin{tabular}{llllll} 
Parameter & $\begin{array}{l}\text { Industry 1 } \\
\text { Sample 1 } \\
\text { I1P1 }\end{array}$ & $\begin{array}{l}\text { Industry 1 } \\
\text { Sample 2 } \\
\text { I1P2 }\end{array}$ & $\begin{array}{l}\text { Industry 2 } \\
\text { Sample 1 } \\
\text { I2P1 }\end{array}$ & $\begin{array}{l}\text { Industry 2 } \\
\text { Sample 2 } \\
\text { I2P2 }\end{array}$ & Unit \\
\hline COD & 2,037 & 3,060 & 670 & 720 & $\mathrm{mgO}_{2} / \mathrm{L}$ \\
BOD & 820 & 1,244 & 1,967 & 2,100 & $\mathrm{mgO}_{2} / \mathrm{L}$ \\
TSS & 1,900 & 3,612 & 1,500 & 1,460 & $\mathrm{mg} / \mathrm{L}$ \\
$\mathrm{pH}$ & 7.5 & 7.7 & 7.2 & 6.9 & - \\
\hline
\end{tabular}

Table 2 | Chemical and physical properties of wastewater from industry 1 (I1)

\begin{tabular}{lllc} 
Parameter & Average value & Recommended effluent values & Unit \\
\hline $\mathrm{pH}$ & 7.56 & $7-8$ & - \\
$\mathrm{TSS}$ & 3,446 & 330 & $\mathrm{mg} / \mathrm{L}$ \\
$\mathrm{COD}$ & 2,050 & 800 & $\mathrm{mg} / \mathrm{L}$ \\
$\mathrm{BOD}$ & 1,060 & 400 & $\mathrm{mg} / \mathrm{L}$ \\
\hline
\end{tabular}

\section{$\overline{\text { RESULTS AND DISCUSSION }}$}

Based on the conducted experiments, effects of wastewater treatment were compared using different coagulants. The coagulant was added to the treated wastewater. In the method of volume coagulation with aluminum sulphate, a decrease of individual parameters characterizing wastewater was noted along with the increase of the coagulant dose. The salt coagulant was added at a dose ranging from $50 \mathrm{mg} / \mathrm{L}$. The chosen dose of the selected salt was directly added into the wastewater sample. Subsequent analyses of the residual levels of COD was then measured. The percent removal of a pollutant was calculated using the following Equations (1):

$\% C O D_{e} \frac{C O D_{\text {in }}-C O D_{\text {out }}}{C O D_{\text {in }}} \times 100 \%$

where:

$C O D_{e}$ - efficiency of COD removal

$C O D_{\text {in }}$ - COD concentration befor treatment/in the inflow $C O D_{\text {out }}$ - COD concentration after treatment/ in the outflow

Results are shown in the following figures, where it was already calculated the efficiency of the treatment after the addition of PAC, PAX and PIX coagulant.

In the first stage, effects of initial COD concentration from two paper industry with different coagulant type and dose was investigated. Initial concentration refers to the values presented in Table 1 . Temperature was $\mathrm{T}=18.9^{\circ} \mathrm{C}$ and $\mathrm{pH}$ value was 7.5. Figure 2 present results for PAC and PIX coagulant.

The comparison of the treatment efficiency for tested wastewater with PAC and PIX coagulant depends on the COD initial concentration for the analysed wastewater samples, nonetheless PAC indicates better COD removal effects, regardless of the COD concentration in the raw wastewater. The highest efficiency was reached for high initial COD in wastewater from IP1. In samples of PAC coagulated wastewater, $1 \mathrm{mg}$ of PAC removed $28 \mathrm{mg}$ of COD 
(a)

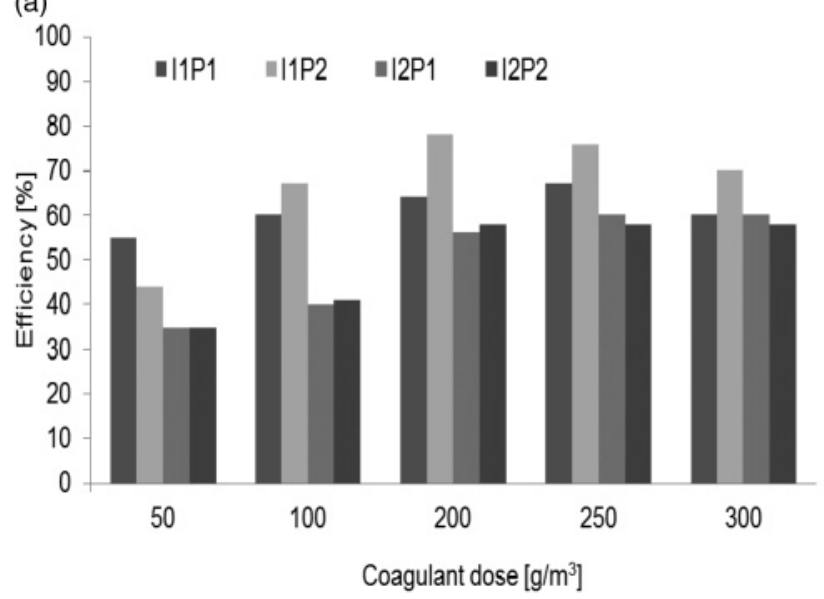

(b)

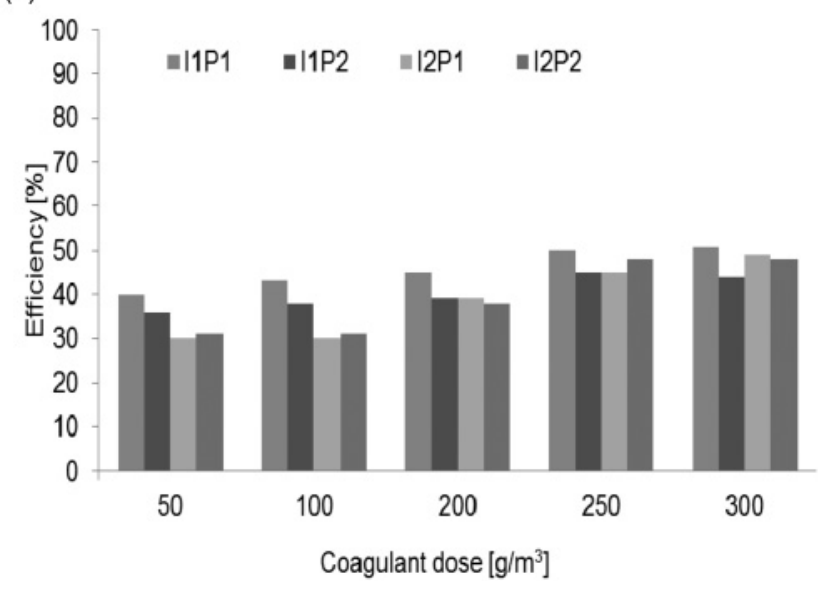

Figure 2 | Efficiency of coagulation process for wastewater from industry I1 and I2 with different dose of PAC (a) and PIX coagulant (b).

and $1 \mathrm{mg}$ of PIX (Figure 2) removed only $15 \mathrm{mg}$ of COD. Direct comparison of the treatment efficiency of the tested wastewaters with PAC and PIX (Figure 2) show that lower doses of PAC provided better treatment results rather than higher PIX doses. This indicates an impact of different anions for coagulation: chloride from PAC and sulfate (VI) from PIX, as well as higher probability of presence of prehydrolysed aluminium forms in PAC than those of iron in PIX. The higher coagulation capacity of PAC than PIX may also be due to the repeated presence of ions in this coagulant with a valence higher than ${ }^{+3}$, i.e. $\mathrm{Al}(\mathrm{OH})^{4+}$, and, in particular, the presence of stable polycation $\mathrm{AlO}_{4}$ $\mathrm{Al}_{12}(\mathrm{OH})_{2}\left(\mathrm{H}_{2} \mathrm{O}\right)_{12}^{7+}$ (Duan \& Gregory 2003; Ratnaweera Q12 2009).

After this study, the project continued by running the same test, with the same coagulant but changing $\mathrm{pH}$ samples; this work has been performed for wastewater from industry I1. Effect of $\mathrm{pH}$ of wastewater was investigate taking into account that in the coagulation process, the $\mathrm{pH}$ is an important parameter influencing the performance of the coagulants (Xiao et al. 2009). The effect of the initial Q13 $\mathrm{pH}$ of the wastewater was studied in range 6.5-8. Figure 3 shows the percent removal of COD vs. coagulant dose for various values of $\mathrm{pH}$. In the range of initial $\mathrm{pH}$ of $6.5-8$, the COD percent removals ranged between 50 and $60 \%$. The minimum percent removal of COD was achieved at acidic condition with $\mathrm{pH}=6.5$. The maximum percent removal of COD was achieved at alkaline condition with $\mathrm{pH}=7.5$ and 8 . The maximum removal efficiencies of $\mathrm{COD}$ at $\mathrm{pH}=7.5$ was $60 \%$, and $61 \%$ at $\mathrm{pH}=8$. In accordance with recommended $\mathrm{pH}$ effluent values presented in Table 2, high efficiency of treatment could be achieved. The test performed by other researchers (Shi et al. 20I6) confirm high COD removal efficiency (83\%) from paper mill
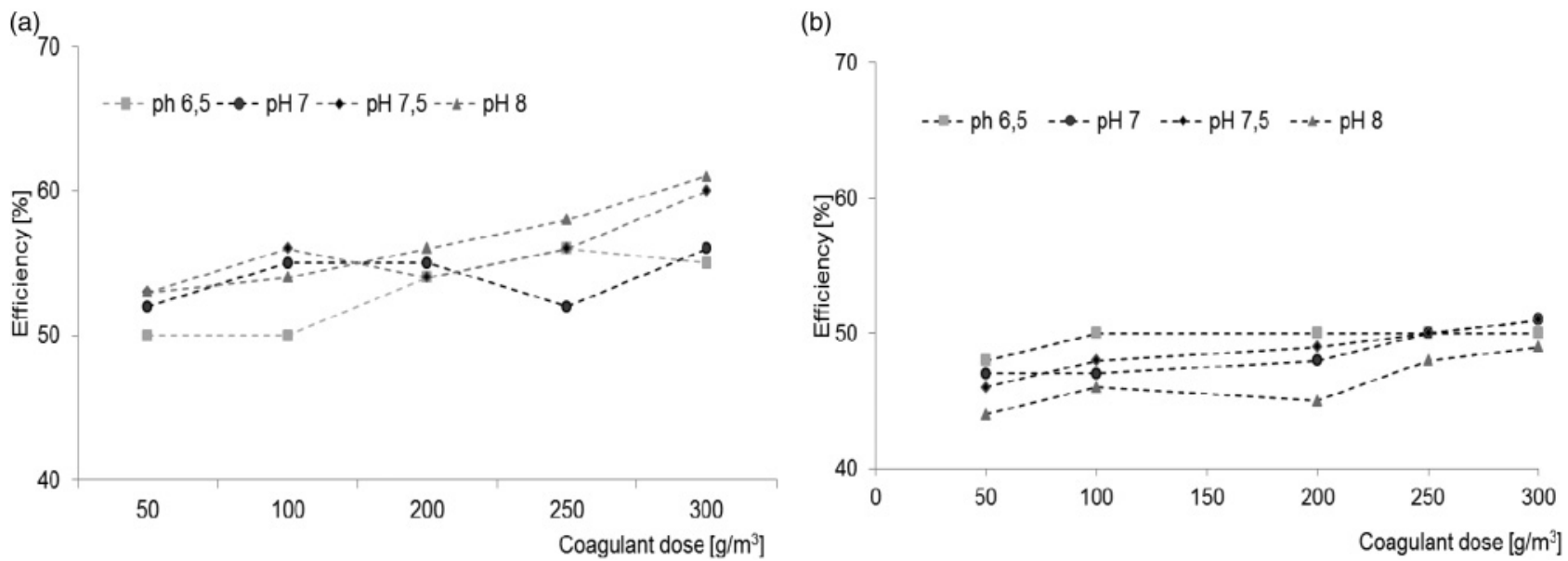

Figure 3 | Efficiency of coagulation process in I1 with different dose of PAC coagulant (a) and PIX coagulant (b). 
wastewater, in coagulation treatment. Indicating that, the initial $\mathrm{pH}$ of the effluent had a tremendous effect on the Q14 COD removal (Choudhary et al. 20I5).

For PIX coagulant (Figure 3(b)) similar results were achieved. In this case, the higher efficiency was reached for two-different $\mathrm{pH}$ (6.5 and 7.5), obtaining in each a 50\% of efficiency, being first achieved with a lower dose of coagulant in the sample with lower $\mathrm{pH}$ (6.5).

Effect of temperature and coagulant type was also tested. The effect of temperature and the addition of the salt coagulant type, on the COD removal efficiency, was investigated for four different temperatures: 11-13-16$18^{\circ} \mathrm{C}$. For these tests, experimental conditions were for $\mathrm{pH}$ values 7.5 and 8 . The effect of adding $50 \mathrm{mg} / \mathrm{L}$ up to $300 \mathrm{mg} / \mathrm{L}$ of PAC and PIX was considered. COD removal as a function of dose for different temperatures are shown in Figure 4(a) for PAC and Figure 4(b) for PIX. This figure shows that an increase in temperature from $11^{\circ} \mathrm{C}$ to $18^{\circ} \mathrm{C}$ cause an increase in the COD removal efficiencies. The rate of COD removal was very high at $18^{\circ} \mathrm{C}$ and lower at $11^{\circ} \mathrm{C}$ for both coagulants, however the test with PAC results show that even at low temperature result can be considered as good. The optimum operating temperature is $18^{\circ} \mathrm{C}$, being the highest COD removal efficiencies observed at this temperature.

According with the results obtained at laboratory scale in-situ test were performed using three types of coagulants considering that the lower dose of one can make better results that higher dose of others. As can be seen in the graph (Figure 5) all the combinations of PAC doses are good enough to consider that it can be used in the wastewater treatment process because the efficiency of the process adding coagulant and let the wastewater sediment without any addition is always higher than $50 \%$, which means that all dose are valuable for the process. PIX coagulant was not so sufficient and did not show this trend, which can be attributed to the low temperature and higher $\mathrm{pH}$ of the wastewater. Many studies has showed a better contaminant removal capacity at higher efficiencies under optimized operating conditions (Ashrafi et al. 20I5).

In pursuance of obtained results, the clear suggestion is that, under in-situ conditions (lower temperature, $\mathrm{pH}$ around 7.5) the addition of PAC is better than PAX or PIX for the coagulation process and may be advantageous. Although it may lead to the higher cost. Efficiency for coagulation with PAC was around 70\%. In comparison with PIX, the PAX coagulant provided slightly better removal of COD levels at all concentration of coagulant as shown in Figure 5. For example, the COD removal by dose $200 \mathrm{mg} / \mathrm{L}$ of PAX and PIX were 55\% and 30\%, respectively. The COD removal by dose $100 \mathrm{mg} / \mathrm{L}$ of PAX and PIX were $42 \%$ and 33\%, respectively. Indeed, for PIX coagulant the sample on site achieves very low values of efficiency, which means that it is imperceptible the effect of the coagulant in this type of wastewater, so it should be carefully considered adding the coagulant or not to the treatment process in the dose of 200 up to $250 \mathrm{~g} / \mathrm{m}^{3}$, because the efficiency becomes lower. At this point, it is helpful to remember that PIX coagulant belongs to the ferric coagulants, that comprise iron sulphates, chlorides and iron chloro-sulphates. They are particularly recommended to for removal of phosphorus content from wastewater, for binding of hydrogen sulphide (a)

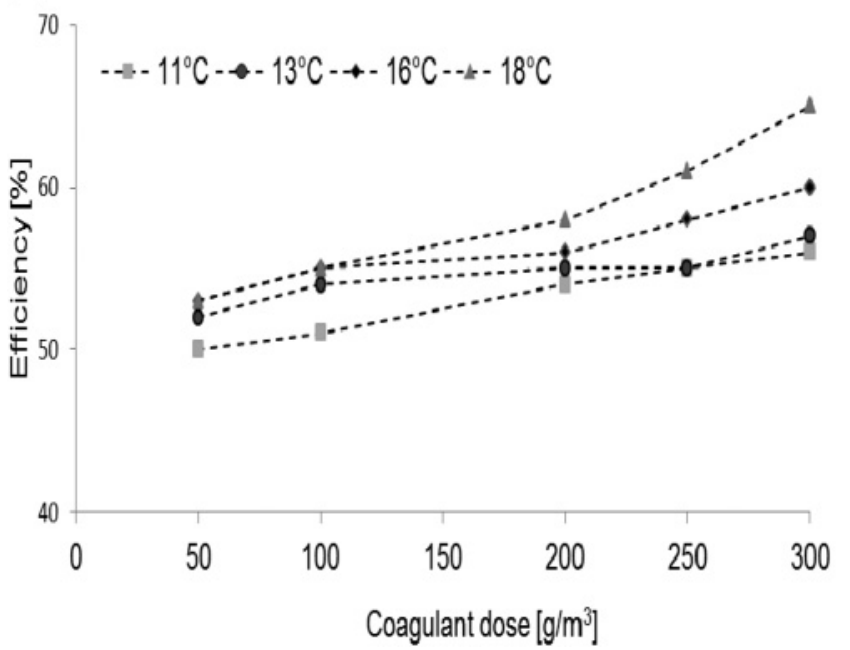

(b)

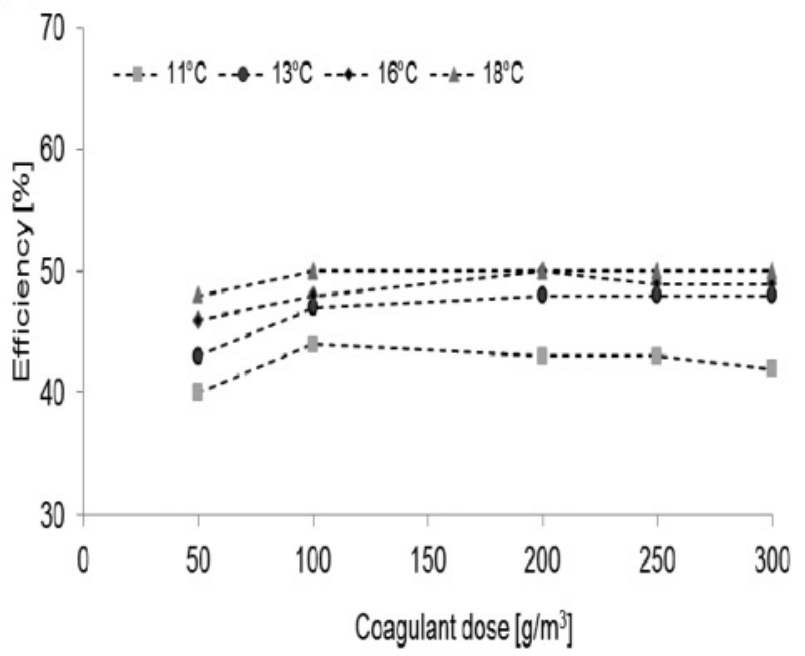

Figure 4 | Efficiency of coagulation process with different dose of PAC coagulant (a) and PIX coagulant (b). 


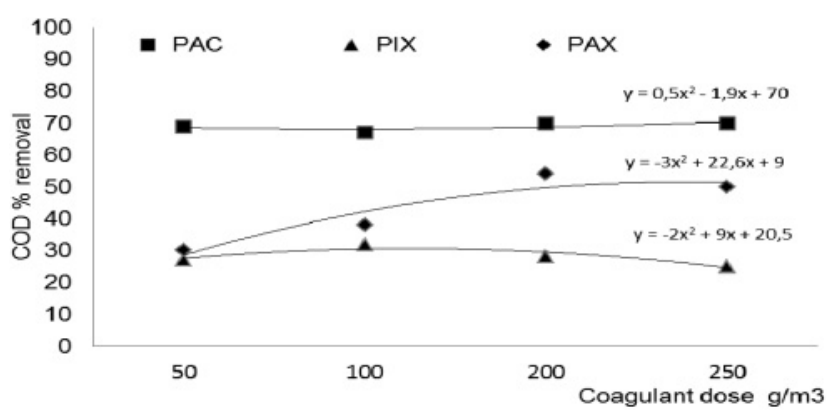

Figure 5 | Efficiency of on-site coagulation process in I1 with different dose and type of coagulant. $\mathrm{T}=13^{\circ} \mathrm{C}$.

and for wastewater sludge conditioning purposes. Changes in COD concentration in sewage for higher temperature coagulated with PAX and PIX are shown in Figure 6. When $\mathrm{Al}^{3+}$ ion dose increases, the degree of removal of the analysed wastewater components increases. After reaching the minimum concentration corresponding to the maximum removal, further increase the coagulant dose results in a deterioration in the parameters of treated wastewater. Such the course of dependence removal $=f$ (coagulant dose) is characteristic of a second-degree polynomial function (2), and so for a parabola describing the removal of COD from coagulated wastewater:

$y=-0.002 x^{2}+0.1282 x+49.318$

The concept of 'matching' the base of obtained results to this the mathematical model is confirmed by the high $\mathrm{R}^{2}$ determination coefficients values of 0.97 and 0.96 e.g. for regular parabolas showing removal of COD with PAX and PIX from coagulated wastewater. Experimental data shows that the application of PAX coagulant in a higher dose than the optimal dose reduces the effectiveness of wastewater treatment by coagulation. A detailed analysis of COD test revealed that PAX was a more effective and a more efficient coagulant than PIX.

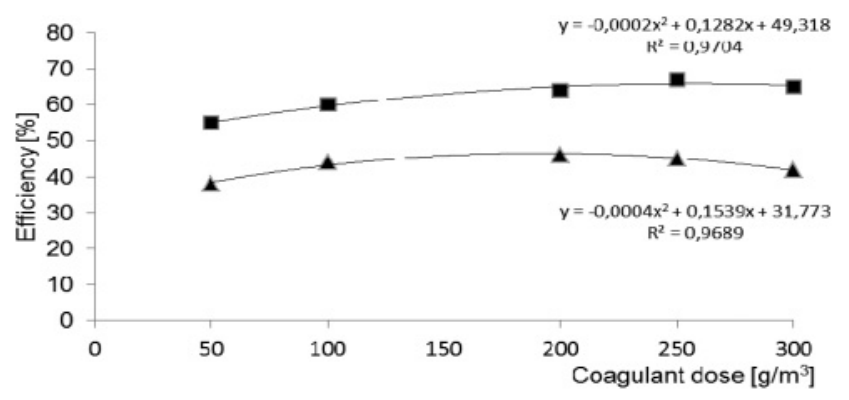

Figure 6 | Efficiency of in-situ coagulation process in I1 with different dose and type of coagulant. $\mathrm{T}=18^{\circ} \mathrm{C}$.
Coagulation is a relatively effective single-treatment method, but combined methods of treatment are more promising technologies for paper mill wastewater treatment (Kamalia \& Khodaparastb 2015). However, the efficiency of Q15 coagulation strongly affects the overall treatment performance; hence, the increase of the efficiency of coagulation stage seems to be a key factor for the improvement of the overall treatment efficiency (Buyukkamacia et al. 2010; Q16 Kamalia \& Khodaparastb 20I5).

\section{Associated costs}

During on-site study the potential for reducing the costs for water intake (Klosok-Bazan \& Boguniewicz-Zablocka 2017) and effluent load by optimizing the water circuits and wastewater treatment was investigated. In-situ tests were used for quantifying the impact of improvement measures and for identifying optimization potential. Rules from BAT was applied (BAT 20Io); tests and calculations showed the effects of a changes on the COD loading reduction. The avoidance of fresh water losses and optimization of wastewater treatment resulted in a significant reduction of COD in the paper machine loop.

These approaches were tested in real case study with an economic and technical comparison made between implemented coagulants. Coagulation process operated under optimal condition involves a total cost of 0.5 EUR per cubic meter of treated paper mill effluent. This cost only includes chemical, dose not include wastewater fee and sludge disposal. However, it was also evaluated that COD reduction in wastewater discharged allows to reduce fee paid about $40 \%$. Cost estimation based on available cost data of chemicals are presented in Table 3. Costs analysis of coagulation was carried out on the basis of prices from 2017, given by Dempol (Polish company). Coagulant dose was calculated for unit dose necessary to reach 50\% COD reduction and then annual demand was estimated.

Figure 7 show dependencies between unit cost (in $\mathrm{PLN} / \mathrm{m}^{3}$ ) and the effect of efficiency (in\%) related to COD removal. Obtained results depend, above all else from unit

Table 3 | Calculated cost

\begin{tabular}{lllll} 
& \multicolumn{4}{l}{ coagulant type } \\
\cline { 3 - 5 } Type of costs & Unit & PIX & PAX & PAC \\
\hline Unit coagulant cost & EUR/L & 1.92 & 2.11 & 2.72 \\
$\begin{array}{l}\text { Cost associated with dose } \\
\text { (annual) }\end{array}$ & EUR & 48,050 & 48,530 & 56,576 \\
& & & & \\
\end{tabular}




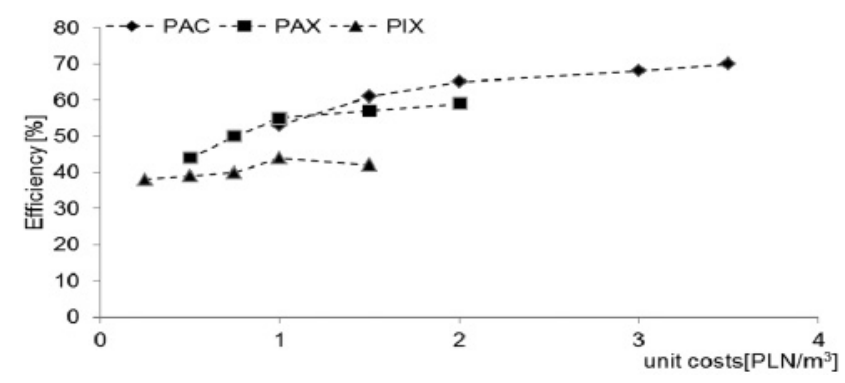

Figure 7 | Unit cost for reaching efficiency of COD removal for different coagulants type.

prices of coagulants. Unit cost coagulant consumption ranges from $0.25 \mathrm{PLN} / \mathrm{m}^{3}$ when using PIX and dose $50 \mathrm{~g} / \mathrm{m}^{3}$ up to 3.5 PLN/ $\mathrm{m}^{3}$-when used PAC and a dose of $300 \mathrm{~g} / \mathrm{m}^{3}$.

Analysing the dependencies presented on Figure 7, it can be seen that the most favourable case is the use of PAX coagulant, and the most unfavourable the use of PIX coagulant. For example, at the unit cost $1 \mathrm{PLN} / \mathrm{m}^{3}$ possible COD removal efficiency is achieved from about $55 \%$ for PAX coagulant, $53 \%$ for PAC, only 44\% for the PIX coagulant. From the point of view of treatment efficiency PAC is preferred coagulant, because at cost unitary $2 \mathrm{PLN} / \mathrm{m}^{3}$ possible is to lower the concentration of this indicator until by $65 \%$. At the same unit cost lower cleaning effect, at the level $59 \%$, is achieved using a PAX coagulant. The obtained level of COD reduction is satisfactory and higher than the results

Q18 obtained by Yuliani (Yuliani et al. 2018) in coagulation-flocculation-UV irradiation/H2O2 method and comparable to this obtained by Yang (Yang et al. 2019). By analyzing the data presented on Figure 7 from economic point of view, the most favorable is the use of PAX, as the recommended value for COD in the effluent do not exceed $800 \mathrm{mg} / \mathrm{l}$ even when unit cost are $0.75 \mathrm{PLN} / \mathrm{m}^{3}$. On the other hand the sewage from the factory is only pre-treated and the recipient is a municipal sewage treatment plant, the value of the COD parameter is strictly determined by the Municipal Wastewater Treatment Plants (WWTP) Council and for the bigger pollution loads the company will pay the bigger fees. While reducing COD, reduction of fees is expected. Combination of higher efficiency and cost-effectiveness are the basic prerequisites for the sustainable treatment.

\section{CONCLUSION}

Wastewater from analysed industries are discharged into municipal sewerage network. Therefore, their parameters do not have to fulfil rigours standard for wastewater discharged directly to the river or ground. Municipal wastewater treatment plant receive wastewater from industry
I1 is calculated for P.E. 44,000 , and it may be sensitive to irregular discharges of high COD polluted sewage. Nevertheless, care for the natural environment and the agreement defining the permissible values of sewage discharged to the municipal sewage system require the industry to use pre-treatment technology for wastewater. Under site-specific condition COD removal yields of $65 \pm 3 \%$ and $53 \pm 2 \%$ were measured for PAC and PAX respectively. The highest efficiency of COD removal was obtained using the PAC coagulant dose, $250 \mathrm{~g} / \mathrm{m}^{3}$ in $\mathrm{pH}$ value 7.5. Efficiency of COD removal from raw wastewater from both industries were different, therefore direct evaluation of different coagulants for COD removal option is difficult to compare due to importance of sitespecific requirements, however some general comments can be made. PAC coagulant tend to have high efficiency in wide range of temperature and initial $\mathrm{pH}$. Further this, and based on demonstrated technological and economic benefit, PAX seems to be most promising for COD control in paper industry due to relatively high efficiency at lower costs. Follow these findings, it could be concluded that the best option for the treatment of the wastewater from paper industries is the coagulation technique, at the optimal operating condition. In the majority of analysed cases, sewage from industrial papermills achieves the applicable legal norms. However, these standards do not currently cover all parameters that may affect the microorganisms of activated sludge or biological deposits, such as the content of heavy metals or sewage toxicity. In large WWTP, industrial wastewater is diluted to a large extent by domestic and rainwater wastewater, but in the case of small biological WWTP, discharge of paper mill wastewater can disturbe their work. In order to reduce the amount of fresh water employed due to limited water resources, industrial activity is currently being forced to recycle part of treated wastewater to hydrpulper (machine for the preparation of paper pulp), this circulation could be very valuable.

\section{REFERENCES}

Abedinzadeh, N., Shariat, M., Monavari, S. M. \& Pendashteh, A. 2018 Evaluation of color and COD removal by Fenton from biologically (SBR) pre-treated pulp and paper wastewater. Process Safety and Environmental Protection 116, 82-91.

Agarwal, S., Basu, R. \& Nath, S. A. 2014 Green computing and sustainable environment - introduction of E-documents and replacement of printed. International Journal of Innovative Research in Information Security 1 (5), 46-53.

Aguilar, M. I., Llor, M., Soler, O. \& Ortu, J. F. 2002 Water Resources 36 (11), 2910-2919. 
Ashrafi, O., Yerushalmi, L. \& Haghighat, F. 2015 Wastewater treatment in the pulp-and-paper industry: a review of treatment processes and the associated greenhouse gas emission. Journal of Environmental Management 158, 146-157.

BAT 2010 Best Available Techniques. Reference Document for the Production of Pulp, Paper and Board Industrial Emissions Directive 2010/75/EU (Integrated Pollution Prevention and Control.

Bhagawati, P. B., Shivayogimath, C. B. \& Ramesh, B. 2018 Studies on electrochemical treatment of pulp and paper mill waste water. In: Proceedings of First International Conference on Energy and

Q20 Environment: Global Challenges, March 09-10, 2018.

Boguniewicz-Zabłocka, J., Capodaglio, A. G. \& Vogel, D. 2017 Analysis of wastewater treatment efficiency in a Soft Drinks Industry. In: E3S Web of Conferences, 19/2017.

Buyukkamaci, N. \& Koken, E. 2010 Economic evaluation of alternative wastewater treatment plant options for pulp and paper industry. Science of the Total Environment 408, 6070-6078.

Central Statistical Office 2018 Environment 2014. Warszawa. Available from: http://stat.gov.pl/obszary-tematyczne/ srodowisko/ochrona-srodowiska-1,44.html (in Polish).

Choudhary, K. A., Kumar, S. \& Sharma, C. 2015 Removal of chloro-organics and color from pulp and paper mill wastewater by polyaluminium chloride as coagulant. Desalination and Water Treatment 53 (3), 697-708.

Deegan, A. M., Shaik, B., Nolan, K., Urell, K., Oelgemöller, M., Tobin, J. \& Morrisey, A. 2oIr Treatment options for wastewater effluents from pharmaceutical companies. International Journal of Environmental Science $\&$ Technology 8, 649-666.

Duan, J. \& Gregory, J. 2003 Advances in Colloid and Interface

Q21

Q22

Georgiou, D., Aivazidis, A., Hatiras, J. \& Gimouhopoulos, K. 2003 Water Reources 37 (9), 2248-2250.

Greenberg, A. E., Clesceri, L. S. \& Eaton, A. D. 2005 Standard Methods Fort the Examination of Water and Wastewater, Vol. 21. American Public Health Association American

Q23 Public Health Association, USA.

Hang, X., Zhu, Y., Chen, X., Shen, W. \& Lutes, R. 2018 Soft-sensing modeling of chemical oxygen demand in photo-electrocatalytic oxidation treatment of papermaking wastewater. Journal of Bioresources and Bioproducts 3 (2), 71-77.

Irfan, M., Butt, T., Imtiaz, N., Abbas, N. \& Shafique, R. 2017 The removal of COD, TSS and colour of black liquor by coagulation-flocculation process at optimized $\mathrm{pH}$, settling and dosing rate. Arabian Journal of Chemistry 10 (2), 2307-2318.

Kamalia, M. \& Khodaparastb, Z. 2015 Review on recent developments on pulp and paper mill wastewater treatment. Ecotoxicology and Environmental Safety 114, 326-342.

Klosok-Bazan, I. \& Boguniewicz-Zablocka, J. 2017 Application of the modeling approach to assess the receiving water impact. In: Proceedings 17th International Multidisciplinary Scientific GeoConference SGEM 2017.

Konieczny, P. 20II Strącanie bezpośrednie i wstępne jako efektywne i przyjazne środowisku metody oczyszczania ścieków komunalnych i przemysłowych. Forum Eksploatatora 3, 82-85. (in Polish).

Loua, I., Gong, S., Huang, X. \& Liu, Y. 2012 Coagulation optimization for low temperature and low turbidity source water using combined coagulants: a case study. Desalination and Water Treatment 46, 107-114.

Molina-Sánchez, E., Leyva-Díaz, J. C., Cortés-García, F. J. \& Molina-Moreno, V. 2018 Proposal of sustainability indicators for the waste management from the paper industry within the circular economy model. Water 10, 1014.

Nwankwere, E. T., Nwadiogbu, J. O., Theophilus, A., Jerry, U. \& Chizoba, A. 2016 Laboratory studies on the treatment of effluent from a pulp and paper mill using activated carbon and sand filter media. American Chemical Science Journal 12 (1), 1-14.

Pokhrel, D. \& Viraraghavan, T. 2004 Treatment of pulp and paper mill wastewater - a review. Science of the Total Environment 333, 37-58.

Rahbar, M. S., Alipour, E. \& Sedighi, R. E. 2006 Color removal from industrial wastewater with a novel coagulant flocculant formulation. International Journal of Environmental Science \& Technology 3 (1), 79-88.

Ratnaweera, H. 2004 Overview of coagulant dosing control. In: Chemical Water and Wastewater Treatment VII, Vol. VII (H. H. Hahn, E. Hoffman \& H. Ødegaard eds.). IWA Publishing, London, pp. 3-13. ISBN: 1843390094.

Regulation, R. P. 2002 Regulation of infrastructure minister on determining the average water consumption standards (Official Journal No.8, Item 70).

Shi, X., Ch, X., Hu, H., Tang, F. \& Sun, L. 2016 Characterization of dissolved organic matter in the secondary effluent of pulp and paper mill wastewater before and after coagulation treatment. Water Science \& Technology 74 (6), 1346-1353.

Thompson, G., Swain, J., Kay, M. \& Forster, C. F. 20oI The treatment of pulp and paper mill effluent: a review. Bioresource Technology 77, 275-286.

Wong, S. S., Teng, T. T., Ahmad, A. L., Zuhairi, A. \& Najafpour, G. 2006 Treatment of pulp and paper mill wastewater by polyacrylamide (PAM) in polymer induced flocculation. Journal of Hazardous Materials 135 (1-3), 378-388.

Xiao, F., Huang, J., Zhang, B. \& Cui, C. 2009 Effects of low temperature on coagulation kinetics and floc surface morphology using alum. Desalination 237, 201-213.

Yang, S., Li, W., Zhang, W., Wen, Y. \& Ni, Y. 2019 Treatment of paper mill wastewater using a composite inorganic coagulant prepared from steel mill waste pickling liquor. Separation and Purification Technology 209, 238-245.

Zhuang, H., Guo, J. \& Hong, X. 2018 Advanced treatment of paper-making wastewater using catalytic ozonation with waste rice straw-derived activated carbon-supported manganese oxides as a novel and efficient catalyst. Polish Journal of Environmental Studies 27 (1), 451-457.

Zodi, S., Louvet, J., Michon, C., Potier, O., Pons, M., Lapicque, F. \& Leclerc, J. 20I Electrocoagulation as a tertiary treatment for paper mill wastewater: removal of non-biodegradable organic pollution and arsenic. Separation and Purification Technology 81, 62-68. 


\section{Author Queries \\ Journal: Water Science \& Technology \\ Manuscript: WST-EM19450}

Q1 Please indicate which authors, if any, are IWA members.

Q2 Boguniewicz-Zalocka (2017) has been changed to Boguniewicz-Zalocka et al. (2017) as per the reference list. Please check and confirm.

Q3 Pokher et al. (2004) has been changed to Pokhrel et al. (2004) as per the reference list. Please check and confirm.

Q4 Molina-Sanchez et al. (2018) has been changed to Molina-Sánchez et al. (2018) as per the reference list. Please check and confirm.

Q5 Kamali et al. (2019) is not listed in the reference list. Please add it to the list or delete the citation.

Q6 Aguilar (2002) has been changed to Aguilar et al. (2002) as per the reference list. Please check and confirm.

Q7 Georgiou (2003) has been changed to Georgiou et al. (2003) as per the reference list. Please check and confirm.

Q8 Duan (2003) has been changed to Duan and Gregory (2003) as per the reference list. Please check and confirm.

Q9 Loua (2012) has been changed to Loua et al. (2012) as per the reference list. Please check and confirm.

Q10 Lenore (2005) is not listed in the reference list. Please add it to the list or delete the citation.

Q11 Yang et al. (2016) is not listed in the reference list. Please add it to the list or delete the citation.

Q12 Ratnaweera (2009) is not listed in the reference list. Please add it to the list or delete the citation.

Q13 Xiao (2009) has been changed to Xiao et al. (2009) as per the reference list. Please check and confirm.

Q14 Kumar et al. (2015) has been changed to Choudhary et al. (2015) as per the reference list. Please check and confirm.

Q15 Kamalia (2015) has been changed to Kamalia and Khodaparastb (2015) as per the reference list. Please check and confirm.

Q16 Buyukkamacia et al. (2010) is not listed in the reference list. Please add it to the list or delete the citation.

Q17 Klosok-Bazan (2017) has been changed to Klosok-Bazan and Boguniewicz-Zablocka (2017) as per the reference list. Please check and confirm.

Q18 Yuliani et al. (2018) is not listed in the reference list. Please add it to the list or delete the citation.

Q19 Please provide missing article title for the reference "Aguilar et al. 2002" references list entry.

Q20 Reference "Bhagawati et al. 2018" is not cited in the text. Please cite else delete from the list.

Q21 Please provide missing article title for the reference "Duan and Gregory 2003" references list entry.

Q22 Please provide missing article title for the reference "Georgiou et al. 2003" references list entry.

Q23 Reference "Greenberg et al. 2005" is not cited in the text. Please cite else delete from the list.

Q24 Reference "Thompson et al. 2001" is not cited in the text. Please cite else delete from the list.

\section{Disclaimer}

This is the uncorrected version of your paper sent to you with the DOI that will be used for the published paper (Version of Record). The uncorrected version will show online while the following services are applied to your manuscript; copyediting, proofreading and typesetting. To see the most current version of your paper, please use the DOI provided. 